\title{
Ear acupuncture and the quality of life of cancer patients: Integrative Review
}

\author{
Elizabeth TA Vallim*, Larissa Marcondes, Jorge VC Felix and Luciana P Kalinke \\ Department of Nursing, Federal University of Paraná, Curitiba, Paraná, Brazil
}

\begin{abstract}
Objective: To perform an integrative review through the available production related to the use of auricular acupuncture as an intervention to improve the QoL of cancer patients.

Methodology: Integrative review of literature with search in electronic bases and virtual health libraries portal VHL, CAPES, CINHAL, PUBMED, WEB of SCIENCE and SCOPUS in the period of January 2017, using as descriptors cancer, neoplasia, auriculotherapy, ear acupuncture and auricular acupuncture. The proposed integrative review took place in six distinct and complementary steps.
\end{abstract}

Results: Six articles with satisfactory evidence of interventions in the clinical symptoms inherent to cancer and its treatment that demonstrated positive impacts of auriculotherapy as an intervention were identified.

Conclusion: The studies related to the subject are not so disponible, they do point to a little explored scientific reality. More clinical trials should be undertaken to strengthen the evidence for effective therapeutic interventions, subsidize practice, and ensure qualified care.

\section{Introduction}

Antineoplastic chemotherapy is the most used therapy for cancer patients in advanced stages; chemical agents, isolated or combined, are responsible for the elimination of tumour cells with both curative and palliative effect. As it is a systemic treatment, a considerable number of healthy cells are impacted, and adverse effects are generated [1].

Searching for better adaptations in the prevention and control of adverse effects, the use of complementary therapies, such as care forms that avoid or minimize the complications resulting from the disease, there has been a permanent effort to improve Quality of Life (QoL) [26]. Ear acupuncture, one of the main complementary therapies, is the intervention proposed for this study. It is indicated in clinical practice as a non-invasive and effective method for cancer patients who have received cancer treatment. It can aid in the control of adverse effects such as: pain, fatigue, insomnia, lack of appetite and dry mouth [7-9].

Thus, the objective of this study was to perform an integrative review on the available production related to the use of ear acupuncture as an intervention to improve the QoL of cancer patients.

\section{Materials and methods}

The methodological way that this research followed corresponds to a branch of Evidence-Based Practice - called Integrative Literature Review [10]. This was divided into six distinct and complementary stages [11], namely: 1) definition of a guiding question; 2) sample selection of the studies; 3 ) categorization of studies; 4) analysis of the studies included in the research; 5) interpretation of the results and 6) the presentation of the review or synthesis of knowledge.

For the study design, the following question was asked: Are the studies that bring the use of ear acupuncture to cancer patients in oncological treatment presenting results that are improving the quality of life?
The search strategy was performed in electronic bases and electronic databases: periodical Capes Portal, CINAHL- Cumulative Index to Nursing and Allied Health Literature, Scopus, Web of Science, PUBMED-National Library of Medicine; and in the Virtual Health Library Portal (VHL): MEDLINE- International Literature in Health Sciences, LILACS- Latin American and Caribbean Literature in Health Sciences and BEDENF- Nursing Database (BDENF) in the period of April 2018.

The descriptors used were the Health Sciences (DeCS) and the Terms of the Medical Subject Headings (MeSH), with the Boolean operators AND and OR, by the following combination: (cancer OR neoplasms) AND (auriculotherapy OR "acupuncture ear" OR "auricular acupuncture"). The selection of the studies occurred with the following inclusion criteria: published studies that addressed the QOL in adult patients with cancer, indexed in databases, full available, without distinction of level of evidence, in Portuguese, English, Spanish and German languages. Duplicate publications and articles without abstract were excluded. The data was systematized and made into two groups.

\section{Results}

We found 199 articles, after applying the eligibility criteria 103 were excluded because they were not available, 12 without an abstract and 15 repeated. From the 37 articles reviewed in full 10 were eligible for responding to the research question.

${ }^{\star}$ Correspondence to: Elizabeth TA Vallima, Department of Nursing, Federal University of Paraná, Curitiba, Paraná, Brazil, E-mail: elizabethvallim@yahoo. com.br

Key words: Cancer; neoplasia; auriculotherapy; acupuncture ear; acupuncture auricular

Received: May 07, 2018; Accepted: May 23, 2018; Published: June 04, 2018 
Regarding the origin of the publications of the 10 articles selected for analysis, all were published in English, these were published in the period of 2003 to 2018 in medical journals. It was found that the methodological approach used in four articles (40\%) were using observational studies, with evidence level 3, four (40\%) were randomized clinical studies, both characterized as level 2 evidence. A prospective cohort study and case report were found.

Analysing the study's theme, the ten articles presented positive results in the use of ear acupuncture, related to the treatment for cancer and the improvement of QoL. The symptoms and side effects that had this improvement were: pain, xerostomy, arthralgia, sleep disorder, constipation, heat and night sweats.

\section{Discussion}

The scarcity of articles on this complementary therapy points to a little explored scientific reality in oncology area with a focus on QoL. Ear acupuncture is an intervention that helps not only the changes related to the physical domains, with diseases that need to control acute or chronic pain, endocrine metabolic or inflammatory, among others, but also in emotional and emotional psychic disorders [7,8,12-14].

\section{Acupuncture as an intervention for the side effects of cancer and treatment}

One of the side effects presented, both related to the disease and to the treatment is pain. Patients with cancer undergoing treatment have a prevalence of chronic pain of $30-50 \%$ and can increase to $70-90 \%$ in patients with advanced disease [15]. Alimi et al. [14] performed a study comparing the acupuncture group with needle applied at electrodermal signal points, with two other groups with needles and mustard seeds, respectively, at placebo points, for the reduction of pain in cancer patients. This study concluded that there was a $36 \%$ reduction of pain after two months of treatment in the group that received ear acupuncture at the points with electrodermal signal.

Crew et al. [16] conducted a pilot study to verify the efficacy and safety of auricular acupuncture in reducing the symptoms of joint pain caused by aromatase inhibitors applied in two groups. After treatment, $64 \%$ of the patients reported moderate pain relief and $71 \%$ reported moderate stress relief. Pirnia et al. [17] in their case report pointed to the improvement of back pain caused by the increase of the cortisol levels of the patient with colon cancer. Another effect was the aid in xerostomia in the Morganstein study [18], this one pointed out that acupuncture increased salivary production, but did not reach equal levels before irradiation, patients also had improvement in physical, emotional and cognitive well-being influencing positively in the QV. Harding et al. [21], Valois et al. [13,22] used ear acupuncture to verify the improvement of heat waves and night sweats. These symptoms are frequent in hormonal treatment used and recommended in cases of prostate, breast and endometrial cancer; however, side effects such as erectile dysfunction, decreased libido, heat and night sweats, among others, have a negative influence on the quality of life of these patients [3]. For symptoms, heat waves and night sweats, Harding et al. [18] mean that $95 \%$ of patients reported a significant decrease in these; for Valois et al. [19], the patients reported improvement of symptoms and frequency; and in the article by Valois et al. [13] the results were better, clinically and statistically significant.

For Shin and Park [19] atrial acupuncture has been shown to be an effective intervention in relieving constipation in women with breast cancer treated with chemotherapy. The improvement of this symptom was also pointed out in the study by Li et al. [20] with post-surgical patients of lung cancer, also with an improvement in the appearance of the faeces to the group that received the auriculoterapia.

The articles by Harding et al. [21], Valois et al. [22] and Rich et al. [23] also brought sleep disorder symptom. Patients with cancer often have this disorder, with an incidence of around $30-50 \%$, compared to $15 \%$ of the general population [24], negatively impacting QoL because it affects well-being [3]. These authors [21-23] reported a significant improvement in patients with disorders to sleep after the use of auriculotherapy.

\section{Ear acupuncture in improving quality of life}

Symptoms due to cancer and chemotherapy affect QoL-related directly impacting patients' daily lives. Auriculotherapy can be an intervention that helps not only the changes related to the physical domains, but also in the emotional domains, personal performance and global QoL. Harding et al. [21] used the Measure Yourself Concerns and Well-being (MYCAW) questionnaire to detect and evaluate symptoms of complaints of general health and well-being and obtained statistically meaningful results, $95 \%$ of patients reported a decrease of physical symptoms and had an improvement in the affected domains like depression, anxiety and panic attack.

Valois et al. [22] used auriculotherapy in 50 patients and found that from nine domains evaluated in the questionnaire Women's Health Questionnaire (WHQ), six presented significant changes in anxiety/ fears; concentration/memory and depressive mood, evidencing that there was an improvement of the wellbeing and the physical health of these patients. In the study by Valois et al. [13], the SF-36 (Health Survey-36) that can be used to evaluate eight physical and psychological domains and obtained meaningful results in reducing symptoms in daily life, work, social life and sleep, mood, concentration with improvement of QoL.

\section{Conclusion}

This integrative review gathered and analysed articles that allowed to conclude the existence of the improvement in the QoL of patients undergoing oncological treatment who used ear acupuncture as a complementary therapy, being a safe, effective and economical method with no serious adverse effects and well accepted by the patients. The studies presented a considerable evidence, indicating the continuity of the clinical use of auriculotherapy in these cases; aiming to promote improvement of the symptoms that affect the patients' QoL. It was identified that the instruments used for the evaluation of QoL have distinctive characteristics and different degree of measurement, it is necessary to intensify the care in choosing the instruments; as this may compromise comparative data on the evidence, confidence intervals, signs and symptoms of QoL of these patients.

\section{References}

1. Santos LPA, Melo MRS, Pereira CU (2012) Incidência de náuseas e vômitos no pósoperatório imediato dos pacientes neurocirúrgicos. Scientia Plena 8. $3 \mathrm{a}$.

2. Garcia SN, Jacowski M, Castro GC, Galdino C, Guimarães PRB, et al. (2015) Os Domínios afetados na Qualidade de Vida em Mulheres com Neoplasia Mamária. Rev Gaúch Enferm 36: 89-96.

3. Santana PXS, Borges JN, Barros AMSM (2015) Qualidade de Vida do Paciente Portador de câncer de Próstata em Hormonioterapia. Ciênc Biol Saúde Unit 2: 111-28.

4. Guimarães AGC, Anjos ACY dos (2012) Caracterização Sociodemográfica e Avaliação da Qualidade de Vida em Mulheres com Câncer de Mama em Tratamento Quimioterápico Adjuvante. Rev Bras Cancerol 58: 581-92.

5. Campos MPO, Hassan BJ, Riechelmann R, Giglio AD (2011) Fadiga relacionada ao câncer: uma revisão. Rev Assoc Med Bras 57: 211-9. 
6. Guimarães RCR, Gonçalves RPF, Lima CA, Torres MR, Silva CSO (2015) Ações de enfermagem frente às reações a quimioterápicos em pacientes oncológicos. $J$ res: fundam Care online 7: 2440-52.

7. Kumar JVR, Uma M (2015) Effectiveness of Acupressure on improving the Quality of Sleep among Cancer Patients. Asian J Nur Edu 5;513-17.

8. Yeh CH, Chien LC, Glick RM, Londen G van, Bovbjerg DH (2015) Auricular point acupressure as an adjunct analgesic treatment for cancer patients: a feasibility study. $J$ Pain Relief 16; 285-93.

9. Kurebayaschi LF, Gnatta JR, Borges TP, da Silva MJ (2012) Applicability of auriculotherapy in reducing stress and as a coping strategy in nursing professionals. Rev Lat Am Enfermagem 20: 980-7. [Crossref]

10. Souza MT, Silva MD da, Carvalho R de (2010) Revisão integrativa: o que é e como fazer. Einstein 8:102-6.

11. Botelho LLR, Cunha CCA, Macedo M (2011) O método da revisão integrativa nos estudos organizacionais. Gestão e Sociedade 5: 121-36.

12. Nicolussi AC, Picharillo C, Saraiva DA, Paula JM de, Okino L, et al. (2012) Qualidade de Vida e Reabilitação dos Pacientes Oncológicos. Rev Cultural e Extensão USP 8: 53-65.

13. Valois B de, Young TE, Thorpe P, Preston J, Degun T (2015) Improving Well-Being of Prostate Cancer Survivors Using the NADA Acupuncture Protocol: A Clinical Outcome Study. Medical Acupuncture 27: 194-205.

14. Alimi D, Rubino C, Pichard-Léandri E, Fernand-Brulé S, Dubreuil-Lemaire ML, et al. (2003) Analgesic Effect of Auricular Acupuncture for Cancer Pain: A Randomized, Blinded, Controlled Trial. J Clin Oncol 21: 4120-6. [Crossref]

15. Miceli AVP (2002) Dor crônica e subjetiva em oncologia. Rev Bras de cancerol 48: 363-73.
16. Crew KD, Capodice JL, Greenlee H, Apollo A, Jacobson JS, et al. (2007) Pilot study of acupuncture for the treatment of joint symptoms related to adjuvant aromatase inhibitor therapy in postmenopausal breast cancer patients. J Cancer Surviv 1: 283-91. [Crossref]

17. Pirnia B, Pirnia K, Teimouri M, Kolahi P (2017) Acupuncture for Back Pain in Colon Cancer: A Case Report. Int J Cancer Manag 10: e15087.

18. Morganstein WM (2005) Auricular Acupuncture in the Treatment of Xerostomia Journal of Chinese Medicine 79: 5-8.

19. Shin J, Park H (2018) Effects of Auricular Acupressure on Constipation in Patients with Breast Cancer Receiving Chemotherapy: A Randomized Control Trial. West J Nur Res 40: 67-83. [Crossref]

20. Li Y, Qi D, Gong L, Qu H, Xu B, et al. (2017) Effect of auricular points treatment combined with constipation after lung cancer surgery. J Cancer Res Ther 13: 844-48. [Crossref]

21. Harding C, Harris A, Chadwick D (2008) Auricular acupuncture: a novel treatment for vasomotor symptoms associated with luteinizing-hormone releasing hormone agonist treatment for cancer. BJU Int 103: 186-90. [Crossref]

22. Valois B de, Young TE, Robinson N, McCourt C, Maher EJ (2012) NADA Ear Acupuncture for Breast Cancer Treatment-Related Hot Flashes and Night Sweats: An Observational Study. Med Acupunct 24: 256-68.

23. Rich T, Porter GW, Ricks-Santi L, Milshtein T, Corbin T (2017) Intermittent 96-Hour Auricular Electroacunpucture for Hot Flashes in Patients with Prostate Cancer: A Pilot Study. Med Acupunct 29: 313-21. [Crossref]

24. Barichello E, Sawada NO, Sonobe HM, Zago MMF (2009) Qualidade do sono em pacientes submetidos à cirurgia oncológica. Rev Latinoam Enferm 17: 481-8.

Copyright: $@ 2018$ Vallima ETA. This is an open-access article distributed under the terms of the Creative Commons Attribution License, which permits unrestricted use, distribution, and reproduction in any medium, provided the original author and source are credited. 